\title{
Potencial do óleo essencial de erva-luísa (Aloysia citriodora Palau) no controle de Fusarium sp. in vitro
}

FREDDO, Á.R. ${ }^{1 *}$; MAZARO, S.M.2; BORIN, M.S.R.2; BUSSO, C.2; CECHIN, F.E.2; ZORZZI, I.C.2; DALACOSTA, N.L. ${ }^{2}$; LEWANDOWSKI, A. ${ }^{2}$

1 União de Ensino do Sudoeste do Paraná - UNISEP, Av. Presidente Kennedy, 2601, Dois Vizinhos - PR, CEP 85660-000, Brasil. 2Universidade Tecnológica Federal do Paraná, Campus Dois Vizinhos, Estrada para Boa Esperança, Km 04, Dois Vizinhos - PR, CEP 85660-000, Brasil. *Autor para correspondência: alvaro.freddo@ hotmail.com.

RESUMO: O presente trabalho teve como objetivo principal avaliar o potencial do uso do óleo essencial de Aloysia citriodora no controle in vitro de Fusarium sp., isolado de plântulas de beterraba infectadas com o mesmo. $O$ trabalho foi realizado por meio de dois experimentos: um sobre o efeito do óleo essencial no crescimento micelial, e outro sobre o efeito na germinação de conídios do fungo. No primeiro trabalho, avaliou-se em delineamento inteiramente ao acaso, o efeito das concentrações $0,0155 \% ; 0,0315 \% ; 0,0625 \% ; 0,125 \% ; 0,250 \%$ e 0,500\% do óleo essencial de $A$. citriodora em placas de Petri ${ }^{\oplus}$ com meio de cultivo BDA, mais a testemunha, com meio BDA puro. Cada placa foi considerada uma repetição, as quais foram incubadas a $24^{\circ} \mathrm{C} \pm 1^{\circ} \mathrm{C}$ e submetidas a fotoperíodo de doze horas. Avaliou-se o crescimento radial do patógeno em função do crescimento micelial do patógeno quando este atingia as bordas da primeira placa. No segundo experimento, as mesmas concentrações foram testadas, nas mesmas condições de incubação, no entanto, em lâminas de microscopia com meio BD. Utilizou-se delineamento inteiramente ao acaso, sendo considerada como unidade experimental cada lâmina utilizada. Avaliou-se 24 horas após a incubação, em microscópio óptico, a germinação dos primeiros vinte conídios visualizados a partir do canto esquerdo superior para o direito. Os resultados do segundo experimento foram expressos em porcentagem de germinação de conídios. Os resultados obtidos permitiram concluir que este óleo essencial possui efeito fungistático e fungicida sobre o crescimento micelial e na germinação de conídios de Fusarium sp.. Além disso este efeito é maior em função do aumento da concentração do óleo essencial.

Palavras-chave: fitopatologia, plantas medicinais, Verbenaceae, Beta vulgarisL.

\begin{abstract}
Essential oil potential herb-luisa (Aloysia citriodora Palau) in the control of Fusarium sp. in vitro. This study aimed to evaluate the potential use of Aloysia citriodora essential oilisolated from beet seedlings infected with it. The study was performed by conducting two experiments evaluating the effect of the essential oil on mycelial growth and fungus conidia germination. In the first study, in a completely randomized design, the effect concentrations $(0.0155 \% ; 0.0315 \% ; 0.0625 \% ; 0.125 \% ; 0.250 \%$ and $0.500 \%)$ of essential oil of $A$. citriodorawas evaluated on Petri® dish with a PDA cultivation medium, plus the control, with half pure PDA. Each plate was taken as a repeat, and incubated at $24^{\circ} \mathrm{C} \pm 1^{\circ} \mathrm{C}$ and a photoperiod of twelve hours. The radial growth of the pathogen, when the first plate was hit by the mycelial growth of the pathogen on its edges was evaluated. In the second experiment, the same concentrations were tested under the same incubationconditions, however, on microscope slides with half PD medium. The design was used completely randomized, each microscope slide used was considered as one experimental unit. Germination of the first 2 conidia strains, viewed from the upper left to the right was evaluated24 hours after incubation, using an optical microscope. The results of the second experiment were expressed as a percentage of conidia germination. The results obtained showed that this essential oil has fungistatic and fungicidal effect on the mycelial growth and at the conidia germination of Fusarium sp., which has a greater effect with increasing concentrations.
\end{abstract}

Keywords: phytopathology, medicinal plants, Verbenaceae, Beta vulgaris L. 


\section{INTRODUÇÃO}

Fungos do gênero Fusarium correspondem à fase anamórfica ou assexual dos gêneros sexuados ou teleomórficos Giberellae Haematonectria, pertencentes ao Filo Ascomycota do Reino Fungi (Massola Júnior \& Krugner, 2011). Os autores relatam ainda, que em diversas culturas estes patógenos são importantes agentes causais de podridões radiculares, murchas vasculares, deterioração de sementes e produção de micotoxinas em grãos armazenados. Em beterraba, Tivelli et al. (2011) relatam que espécies do gênero Fusarium podem causar tombamento de plântulas.

O controle de doenças causadas por fungos na agricultura é realizado por diversos métodos, dentre estes, o principal é por meio da utilização de fungicidas químicos no tratamento de sementes e órgãos foliares. Entretanto, Neves \& Neves (2007), relatam que, com relação ao uso de agroquímicos, a sociedade tem demandado produtos orgânicos isentos de pesticidas, buscando melhor qualidade dos alimentos. Além disso, o uso intensivo e indiscriminado de agroquímicos tem causado diversos problemas no ambiente, como por exemplo: contaminação de água, solos e animais; intoxicação de agricultores; eliminação de microrganismos benéficos e o surgimento de resistência em fitopatógenos, insetos e plantas daninhas (Schwan-Estrada, 2009).

Neste sentido, as plantas medicinais podem ser exploradas na obtenção de pesticidas naturais, pelo uso de seus extratos brutos e/ou óleos essenciais (Morais, 2009), os quais podem ter ação fungitóxica direta (inibindo o crescimento micelial e germinação de esporos) (Schwan-Estrada et al., 2000).

A erva-luísa (Aloysia citriodora Palau) é um arbusto grande da família Verbenaceae, muito ramificado, ereto, com aroma de citral, de 2 a 3 metros de altura, nativo da América do Sul, provavelmente Chile. Esta planta é cultivada em jardins e hortas domésticas no sul do Brasil, principalmente para fins medicinais e ocasionalmente como condimentar na culinária, para temperar saladas e recheios (Lorenzi, 2008).

Esta planta possui em seu óleo essencial, diversos componentes, como o citral (Ali et al., 2011), geranial, neral e o limoneno (Argyropoulou et al., 2007). Diversos trabalhos in vitro relatam o seu potencial antibacteriano (Sartoratto et al., 2004; Ohno et al., 2003; Duarte et al., 2007; Ali et al., 2011), antimicrobiano (Escobar et al., 2010) e antifúngico (Duarte et al., 2005; Ali et al., 2011; López et al., 2004; Combrinck et al., 2011; Lozada et al., 2012).

Este trabalho teve como objetivo avaliar a eficiência do uso de óleo essencial de A. citriodora, no controle in vitro do crescimento micelial e da germinação de conídios de Fusarium sp., isolados de plântulas de beterraba.

\section{MATERIAL E MÉTODO}

As plantas de Aloysia citriodora Palau (Verbenaceae) foram cultivadas na Horta do Campus Dois Vizinhos da UTFPR. Para extração do óleo essencial das plantas, seguiu-se a metodologia descrita por Paulus et al. (2013) para a espécie. As plantas foram cortadas no mês de maio, no início da manhã. Na data da coleta as plantas estavam em estádio vegetativo com aproximadamente 30 a 50 $\mathrm{cm}$ de altura. Uma exsicata da espécie foi coletada e depositada no Herbário Botânico do Campus Dois Vizinhos da UTFPR, onde foi realizada a identificação taxonômica pelo curador do herbário, sendo que o código do depósito foi registrado sob o número DVPR 842.

Logo após o corte, as folhas foram separadas e seccionadas em porções menores. Após, foram colocadas em aparelho de hidrodestilação, modelo Clevenger do Laboratório da Horta, para extração do óleo essencial.

Foram realizados dois experimentos no Laboratório de Fitossanidade da UTFPR Campus Dois Vizinhos. O primeiro experimento avaliou o efeito do óleo essencial no crescimento micelial e o segundo na germinação de conídios de Fusarium $\mathrm{sp}$. O isolado utilizado no trabalho foi obtido a partir de plântulas de beterraba infectadas com Fusarium sp. O patógeno foi cultivado em meio BDA (batata dextrose ágar), incubado em câmara de crescimento a $24^{\circ} \mathrm{C} \pm 1^{\circ} \mathrm{C}$, com fotoperíodo de 12 horas, sendo repicado até a obtenção de colônias puras do fungo.

No primeiro experimento, avaliou-se o crescimento radial do patógeno em placas de Petri®. Os tratamentos consistiram de concentrações de óleo essencial de $A$. citriodora $(0,0155 \%$; $0,0315 \% ; 0,0625 \% ; 0,125 \% ; 0,250 \%$ e $0,500 \%$ ) mais a testemunha (meio de cultivo BDA puro), em delineamento inteiramente ao acaso, com quatro repetições por tratamento, sendo cada placa de Petriß considerada como repetição.

O meio de cultura BDA utilizado no experimento foi esterilizado em autoclave a temperatura de $120^{\circ} \mathrm{C}$ por vinte minutos. O óleo essencial foi incorporado ao meio após o resfriamento deste (temperatura em torno de $40^{\circ} \mathrm{C}$ ) sendo em seguida vertido em placas de Petriß de 8 $\mathrm{cm}$ de diâmetro. Após, as placas foram esterilizadas abertas em câmara de fluxo laminar, com luz ultravioleta germicida, por dez minutos.

O patógeno foi manipulado em câmara de fluxo laminar sendo colocado no centro de cada placa, na forma de disco de micélio puro, com o 
diâmetro de $7 \mathrm{~mm}$. Após, as placas foram tampadas e vedadas com papel filme plástico. Com caneta de retroprojetor, foram marcados nas tampas os diâmetros $\mathrm{A} \mathrm{e} \mathrm{B}$, de forma perpendicular, nos quais foram realizadas as medições para avaliação do crescimento radial dos fungos.

As placas foram acondicionadas em câmara de crescimento submetidas à temperatura de $24^{\circ} \mathrm{C} \pm 1^{\circ} \mathrm{C}$ e fotoperíodo de doze horas. $\mathrm{O}$ experimento encerrou-se quando a primeira placa foi atingida nas bordas pelo crescimento radial do fungo, tendo isto ocorrido em quatro dias (96 horas).

No segundo experimento seguiu-se a mesma metodologia de incorporação do óleo essencial ao meio de cultivo conforme o primeiro experimento. Neste trabalho, avaliou-se a germinação de conídios de Fusariumsp. em função de concentrações $(0,0155 \% ; 0,0315 \% ; 0,0625 \% ; 0,125 \% ; 0,250 \%)$ de óleo essencial de $A$. citriodora, diluído em meio BD (batata dextrose) mais a testemunha (meio BD puro). Este experimento foi realizado em delineamento inteiramente ao acaso com cinco repetições para cada tratamento. As unidades experimentais consistiram de uma lâmina para microscopia com $1 \mathrm{~mL}$ do tratamento.

O inóculo de Fusarium sp. foi proveniente de placa de Petri com meio BDA, cultivado por dez dias. Para obtenção da suspensão de conídios foi adicionado $20 \mathrm{~mL}$ de água destilada e esterilizada na placa. Com auxílio de escova de cerdas macias, procedeu-se a raspagem das colônias. Em seguida, as suspensões foram filtradas em camada dupla de gases esterilizadas.

Para serem adicionadas ao meio de cultura procedeu-se a calibração da suspensão de conídios em Câmara de Neubawer (hemacitômetro), para 2,2 $X 10^{6}$ conídios $\mathrm{mL}^{-1}$. As lâminas foram primeiramente esterilizadas em autoclave a $120^{\circ} \mathrm{C}$ por 20 minutos e receberam $1 \mathrm{~mL}$ dos tratamentos com a suspensão do inóculo de conídios de Fusarium sp. As lâminas com seus respectivos tratamentos e o inóculo do patógeno, foram acondicionadas em caixas plásticas transparentes esterilizadas, forradas com papel filtro esterilizado e umedecido com água deionizada. Desta forma, as caixas plásticas foram acondicionadas em câmara de crescimento a $24^{\circ} \mathrm{C} \pm 1^{\circ} \mathrm{C}$, no escuro, por 24 horas.

A avaliação deste experimento foi realizada mediante a contagem da germinação dos primeiros vinte conídios visualizados de Fusarium sp., em microscópio óptico, a partir do canto esquerdo superior e em direção ao canto direito superior da lâmina. Consideraram-se germinados os conídios que possuíam iniciação do tubo germinativo de forma visível ao avaliador.

Os resultados obtidos nos experimentos foram submetidos à análise estatística.
Primeiramente verificou-se o atendimento da pressuposição do modelo matemático por meio de teste de normalidade com o Teste de Lilliefors. Os dados com distribuição normal foram submetidos à análise de variância e análise de regressão.

\section{RESULTADO E DISCUSSÃO}

O crescimento micelial de Fusarium sp. foi influenciado pelas concentrações de óleo essencial em meio BDA testadas in vitro, sendo que o aumento da dosagem resultou no menor crescimento do fungo. Observou-se também o efeito fungicida a partir da concentração de $0,125 \%$ de óleo essencial de A. citriodora (Figura 1).

Resultados obtidos na literatura corroboram com os obtidos no presente trabalho para o gênero Fusarium. López et al. (2004) relatam que o crescimento micelial in vitro de Fusarium verticillioides foi significativamente reduzido nas faixas de concentração de óleo essencial de $A$. citriodora em meio de cultura entre $0,025 \%$ a $0,05 \%$.

Lozada et al. (2012), afirmam que com a utilização de óleo essencial desta espécie e de outras espécies de Aloysia, em teste in vitro, o crescimento do fungo Moniliophthoraroreri, causador de moniliniose em cacau, foi reduzido a partir da dosagem de $0,2 \%$ e ocorreu inibição total do micélio do patógeno nas dosagens de $0,8 \%$ a $1 \%$.

Bouchra et al. (2003), relatam que na concentração de 0,025\% em meio BDA, o óleo essencial desta planta reduziu o crescimento micelial in vitro, nas taxas de $69,4 \%$ para $B$. cinerea, $68,2 \%$ para Phytophthora citriophthora, $44,4 \%$ para Penicillium digitatum e em 40,4\% para Geotrichum citri-aurantii.

A concentração mínima necessária de óleo essencial de $A$. citriodora para inibir $100 \%$ do crescimento micelial in vitro dos patógenos Colletotrichum gloeosporioides do abacate e da manga, Alternaria citrii de laranjas, Botrytis cinérea de uvas foi de $0,2 \%$, e para Penicillium digitatum de laranjas e Lasiodio plodiatheobramae de mangas foi de 0,3\% (Combrinck et al., 2011).

A germinação de conídios de Fusarium sp. também foi influenciada pelas concentrações de óleo essencial de $A$. citriodora testadas, sendo observado nesta variável, um comportamento linear decrescente, com o aumento da concentração em meio de cultura BD (Figura 2). A cada aumento de $0,0625 \%$ da concentração do óleo essencial utilizado no tratamento das sementes, houve diminuição de $10,24 \%$ na germinação de conídios do patógeno. O controle da germinação dos esporos dos fungos também é importante no controle das doenças de plantas, de acordo com Massola Júnior \& Krugner (2011), o esporo é um elemento de dispersão do

Rev. Bras. PI. Med., Campinas, v.18, n.2, p.558-562, 2016. 


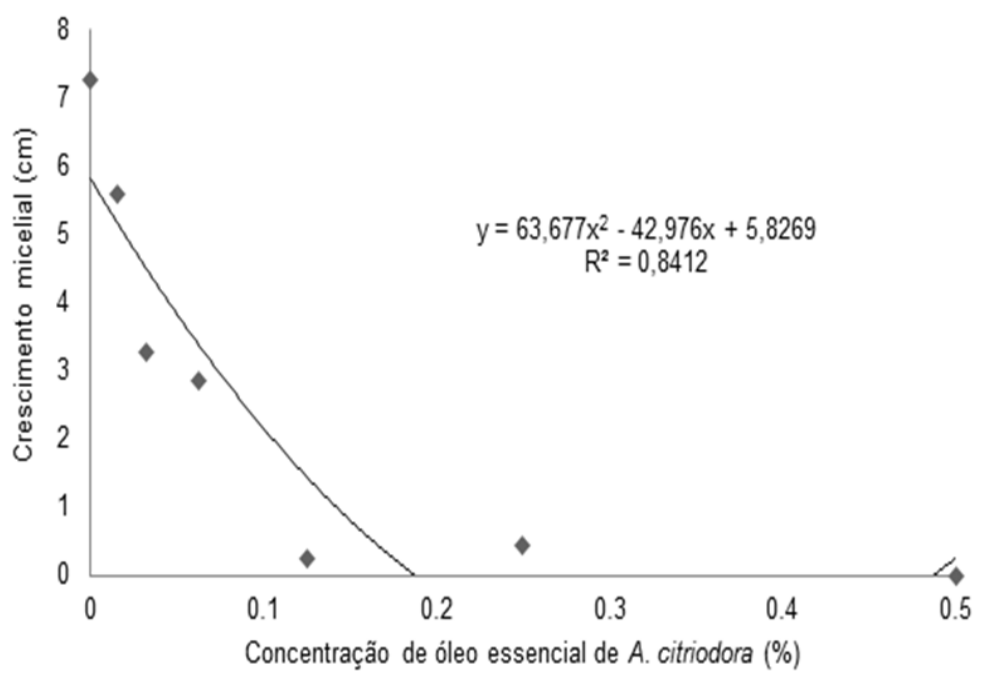

FIGURA 1. Crescimento micelial de Fusarium sp. in vitro, em função de concentrações de óleo essencial de A. citriodora em placas de Petri contendo meio BDA, 96 horas após incubação em câmara de crescimento a $24^{\circ} \mathrm{C} \pm 1^{\circ} \mathrm{C}$ e fotoperíodo de 12 horas.

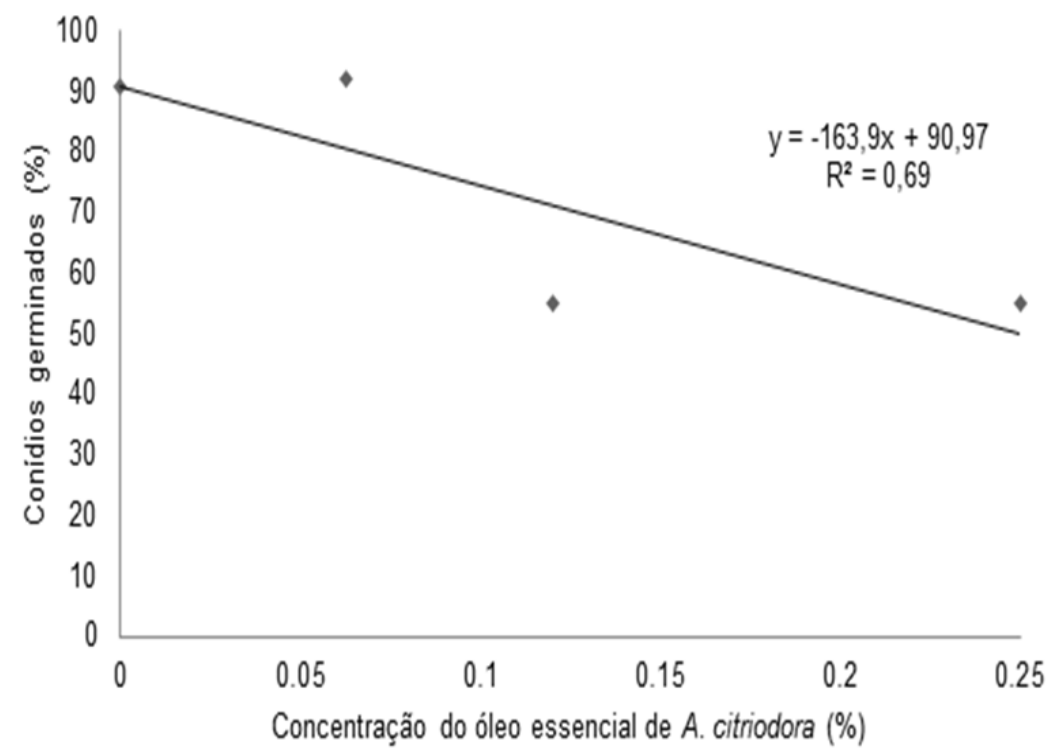

FIGURA 2. Porcentagem de germinação de conídios de Fusarium sp. in vitro, em função de concentrações de óleo essencial de $A$. citriodora em lâminas de microscopia, contendo meio BD, 24 horas após incubação em câmara de crescimento a $24^{\circ} \mathrm{C} \pm 1^{\circ} \mathrm{C}$ e fotoperíodo de 12 horas.

fungo, capaz de gerar um novo indivíduo.

Dentre os componentes do óleo essencial que podem ter tido efeito no fungo Fusariumsp., estão o citral e o limoneno. De acordo com Paulus et al. (2013), a composição química do óleo essencial de $A$. citriodora, espécie do mesmo gênero, para o mês de maio na região de Dois Vizinhos, PR, sob mesmas condições de coleta e extração, demonstra como principais componentes químicos, o limoneno $(14,10 \%)$ e o citral (geranial + neral) $(49,69 \%)$.

Limoneno extraído das plantas das plantas Mentha spicatae Anethum sowa, também é relatado com efeito antifúngico a vários patógenos humanos (Aggarval et al., 2002). Enquanto que o citral extraído de Lippia alba (Aloysia alba) é relatado como antifúngico a Aspergillus fumigatus e Candida krusei (Mesa-Arango et al., 2009). Extraído de citronela (Cymbopogon citratus), é relatado com potencial de controle a várias espécies de fungos, como Candida albicans, Alternaria citrii, A. fumigatus, Aspergillus oryzae, Fusarium oxysporum, Fusarium solani, Helminthosporium compactum, Sclerotium rolfsii, Trichophyton mentagrophytes (Pattnaik et al., 1997) e Rhizoctonia solani (Gonçalves, 2012).

Os resultados obtidos no presente experimento, permitiram concluir que o óleo de A. citriodora possui efeito fungistático e fungicida 
in vitro no controle do crescimento micelial e na germinação de conídios de Fusarium sp., isolado de plântulas de beterraba infectadas, sendo maior o efeito conforme o aumento da dosagem testada.

\section{REFERÊNCIA}

AGGARVAL, K.K.; et al. Antimicrobial activity profiles of the two enantiomers of limonene and carvone isolated from the oils of Menthaspicata and Anethumsowa. Flavour and Fragance Journal, v.17, n.1, p. 59-63, 2002.

ALI, H.F.M.; et al. Evaluation of antioxidant and antimicrobial activity of Aloysiatriphylla. Electronic Journal of Environmental, Agricultural and Food Chemistry, v. 10, n. 11, p. 3044-3053, 2011.

ARGYROPOULOU, C.; et al. Chemical composition of the essential oil from leaves of Lippiacitriodora $\mathrm{H}$. B. K. (Verbenaceae) at two developmental stages. Biochemical Systematics and Ecology, v. 35, p. 831-837, 2007.

BOUCHRA, C.; et al. Antifungal activity of essential oils from several medicinal plants against four postharvest citrus pathogens. Phytopathologia Mediterranea, v.42, p. 251-256, 2003.

COMBRINCK, S.; et al. In vitro activity of eighteen essential oils and some major components against common postharvest fungal pathogens of fruit. Industrial Crops and Products, v. 33, p. 344-349, 2011.

DUARTE, M.C.T.; et al. Anti-Candida activity of Brazilian medicinal plants.Journal of Ethnopharmacology, v. 97, n. 2, p. 305-311, 2005.

DUARTE, M.C.T.; et al. A. Activity of essential oils from Brazilian medicinal plants on Escherichia coli.Journal of Ethnopharmacology, v. 111, n. 2, p. 197-201, 2007.

ESCOBAR, P.; et al. Chemical composition and antiprotozoal activities of Colombian Lippia spp essential oils and their major components. Memórias do Instituto Osvaldo Cruz, v. 105, n. 2, p. 184-190, 2010.

GONÇALVES, A.H. Atividade fungitóxica dos óleos essenciais de LippiasidoidesCham. e de Cymbopogon citratus (D.C.) Stapf. no controle de fitopatógenos do feijoeiro comum. 2012. 90p. Dissertação (Mestrado-Área de Concentração em Produção Vegetal) - Programa de Pós-Graduação em Produção Vegetal, UFT, Gurupi.

LÓPEZ, A.G.; et al. Aromatic plants essential oils activity on Fusarium verticillioides Fumonisin $\mathrm{B}_{1}$ production in corn grain. Mycopathologia, v. 158, p. 343-349, 2004.
LORENZI, H. Plantas medicinais no Brasil: nativas e exóticas. 2 ed. Nova Odessa: Instituto Plantarum, 2008, 544p.

LOZADA, B.S.; et al.In vitro effect of essential oils of three Lippia species on Moniliophthora roreri (Cif. and Par.) Evans et al., causative agent of moniliasis of cocoa (Theobroma cacao L.). Acta Agronomica, v. 61, n. 2, p. 94-102, 2012.

MASSOLA JÚNIOR, N.S.; KRUGNER, T.L. Fungos fitopatogênicos.In: AMORIM, L.; REZENDE, J.A.M.; BERGAMIN FILHO, A. Manual de Fitopatologia 1: Princípios e Conceitos. $4^{\mathrm{a}}$ ed. São Paulo: Agronômica Ceres, 2011.p. 149-206.

MESA-ARANGO, A.C.; et al. Citral and carvone chemotypes from the essential oils of Colombian Lippia alba (Mill.) N. E. Brown: composition, citotoxity and antifungal activity. Memórias do Instituto Oswaldo Cruz, v.104, n.6, p. 878-884, 2009.

MORAIS, L.A.S. Óleos essenciais no controle fitossanitário. In: BETTIOL, W.; MORANDI, M.A.B. Biocontrole de doenças de plantas: uso e perspectivas. $1^{\mathrm{a}}$ ed. Jaguariúna: Embrapa Meio Ambiente, 2009, p. 139-152.

NEVES, M.C.P.; NEVES, J.F. Agricultura Orgânica e Produção Integrada: diferenças e semelhanças. Documentos 237. $1^{\text {a }}$ ed. Seropédica: EMBRAPA Agrobiologia, 2007, 20p.

OHNO, T.; et al. Antimicrobial activity of essential oils against Helicobacterpylori. Helicobacter, v. 8, n. 3, p. 207-215, 2003.

PATTNAIK, S.; et al. Antibacterial and antifungal activity of aromatic constituintes of essential oils. Microbios, v.89, p. 39-46,1997.

PAULUS, D.; et al.Teor e composição química do óleo essencial e crescimento vegetativo de Aloysiatriphyllaem diferentes espaçamentos e épocas de colheita. Revista Ceres, v.60, n.3, p. 372-379, 2013.

SARTORATTO, A.; et al. Composition and antimicrobial activity of essential oils from aromatic plants used in Brazil. Brazilian Journal of Microbiology, v. 35, n. 4, p. 275-280, 2004.

SCHWAN-ESTRADA, K.R.F. Extratos vegetais e de cogumelos no controle de doenças de plantas. Horticultura Brasileira, v.27, n.2, p. 4038-4045, 2009.

SCHWAN-ESTRADA, K.R.F.; et al.Uso de extratos vegetais no controle de fungos fitopatogênicos. Revista Floresta, v. 30, n. 1/2, p. 129-137, 2000.

TIVELLI, S.W.; FACTOR, T.L.; TERAMOTO, J.R.S.; FABRI, E.G.; MORAES, A.R.A.; TRANI, P.E.; MAY, A. Beterraba: do plantio à comercialização. $1^{\text {a }}$ ed. Campinas: Instituto Agronômico, 2011, 45p. 